\title{
Pengembangan Atraksi Wisata Minat Khusus Berbasis Nilai Tradisi Makotek Di Desa Wisata Munggu Badung Bali
}

Winda Kusumawati Supandi a, 1, I Made Adikampana 2 a, 2

${ }^{1}$ windakusumawatisupandi@gmail.com, ${ }^{2}$ adikampana@unud.ac.id

a Program Studi Sarjana Destinasi Pariwisata, Fakultas Pariwisata,Universitas Udayana, Jl. Dr. R. Goris, Denpasar, Bali 80232 Indonesia

\section{Abstract}

Makotek tradition is believed as a tradition to ward off bad omens which is practiced twice a year at Kuningan Day by Munggu villagers. In addition to the function of Makotek tradition as religious ritual, it also has a function as tourism attraction. This research aims to identify the value of Makotek tradition and gives some recommendation about tourism attraction development based on Makotek tradition value hence the stakeholder at Munggu Tourism Village can get additional reference to develop various tourism activities. This research uses qualitative method and applies tourism attraction concept, tourism attraction development concept, and special interest tourism concept.

Makotek tradition value were: 1) presentations value of Makotek are talent value, skill value, and medium value; 2) content value of Makotek are knowledge value, ethnic value, intuition value, concept value, life value (morality value, social value, religion value); 3) appearance value of Makotek are form value (shape value and structure value). Special interest tourism attraction developments that can be done were: 1) develop attractions with something to see criteria that represents content value (knowledge and life value) of Makotek tradition and meets enriching and learning aspect; 2) develop attractions with something to do criteria that represents presentation value (skill, talent and medium value), content value (social, knowledge, intution, concept value), appearance value (shape and structure value) of Makotek tradition and meets rewarding, enriching, adventuring, and learning aspect; 3) develop attractions with something to buy criteria that represents presentation value (skill value) of Makotek Tradition and meets rewarding aspect.

Keyword: Special Interest Tourism Attraction Development, Makotek Tradition Value, and Munggu Tourism Village

\section{PENDAHULUAN}

Salah satu desa wisata yang ditetapkan lewat Peraturan Bupati Badung no. 47 tahun 2010 tentang Penetapan Kawasan Desa Wisata di Kabupaten Badung adalah Desa Wisata Munggu, Kecamatan Mengwi. Setelah dilakukan inventarisasi potensi wisata, ditemukan salah satu potensi wisata budaya yaitu Tradisi Makotek, sebuah bentuk tradisi tradisional untuk tolak bala yang masih dilakukan masyarakat Desa Munggu setiap Hari Raya Kuningan atau 6 bulan sekali. Walaupun menjadi salah satu atraksi wisata, nilai sakral Tradisi Makotek perlu dihormati dan dilindungi.

Perlu dikembangkan atraksi wisata yang memanfaatkan potensi alam, sosial budaya, dan buatan manusia namun tetap menjadikan Tradisi Makotek sebagai basis pengembangan untuk menonjolkan jati diri masyarakat Desa Munggu. Karena memanfaatkan tradisi lokal yang sakral, pengembangan atraksi wisata di Desa Wisata Munggu dapat juga merujuk pariwisata minat khusus. Hal dilakukan dengan harapan pariwisata yang berkembang di Desa Wisata Munggu tak hanya mementingkan kuantitas, namun juga dapat menyaring wisatawan berkualitas dan mampu mewujudkan pariwisata berkelanjutan.
Penelitian terdahulu yang terkait yaitu "Tradisi Makotek di Desa Munggu, Badung di Era Global" (Pradana, 2016), menjelaskan dengan detail pelaksanaan Tradisi Makotek dan Tradisi Makotek sebagai budaya lokal tradisional yang dilihat dari perspektif modern di era global. Sementara penelitian ini mengacu pada posisi Tradisi Makotek sebagai potensi wisata yang dijadikan basis pengembangan atraksi minat khusus agar memperkaya kualitas pariwisata di Desa Wisata Munggu. Selain itu karena perkembangan pariwisata di Desa Wisata Munggu juga masih berada pada tahap awal, dibutuhkan masukan terutama produk pariwisata apa yang dapat ditawarkan kepada wisatawan.

Maka perlu diadakan penelitian tentang pengembangan atraksi wisata minat khusus berbasis nilai Tradisi Makotek di Desa Wisata Munggu, Badung, Bali. Penelitian ini bertujuan untuk mengidentifikasi nilai yang terkandung dalam Tradisi Makotek dan mengembangkan atraksi wisata minat khusus berbasis nilai Tradisi Makotek.

Penelitian ini menggunakan menggunakan beberpa konsep, antara lain: 1) konsep nilai seni pertunjukan (Sumarjo, 2000) yang membantu 
proses pengidentifikasian nilai seni pertunjukan yaitu nilai pengungkapan (presentation), isi (content), penampilan (appearance); 2) konsep pengembangan atraksi wisata (Yoeti, 1997) yang menjadi bentuk pengembangan yang bisa diterapkan seperti something to see, something to do, something to buy; serta 3) konsep pariwisata minat khusus (Fandeli dalam Sudana, 2013) yang menekankan aspek rewarding, enriching, adventuring, learning (REAL) dalam pengembangan pariwisata.

\section{METODE PENELITIAN}

Penelitian dilakukan di Desa Munggu, Kecamatan Mengwi, Kabupaten Badung, Provinsi Bali. Desa Wisata Munggu berarak sekitar 14 km dari pusat Kota Denpasar. Desa Wisata Munggu terletak di jalur yang strategis karena berbatasan langsung dengan Kabupaten Tabanan dan merupakan jalur menuju Pantai Tanah Lot. Penelitian ini dilakukan dari 23 Februari 2019 hingga 3 Agustus 2019.

Sumber data yang digunakan dalam penelitian ini adalah data primer dan data sekunder. Data primer yang digunakan pada penelitian ini adalah sejarah Tradisi Makotek, perkembangan pariwisata Desa Wisata Munggu, potensi wisata Desa Wisata Munggu, atraksi wisata Desa Wisata Munggu, dan nilai Tradisi Makotek. Data sekunder yang digunakan pada penelitian ini adalah profil Desa Munggu, sejarah Desa Munggu, dan bentuk Tradisi Makotek.

Teknik pengumpulan data dalam penelitian ini, yaitu observasi, wawancara dan dokumen. Observasi dilakukan untuk mengamati perkembangan pariwisata di Desa Wisata Munggu. Wawancara dilakukan untuk memperoleh data nilai Tradisi Munggu. Sedangkan dokumen digunakan untuk memperoleh data mengenai profil dan sejarah Desa Wisata Munggu.

Teknik analisis data yang digunakan dalam penelitian ini adalah teknik analisis data kualitatif menurut Seiddel (Bungin, 2007: 147). Dalam penelitian ini, peneliti mencatat dari hasil wawancara dan observasi sehingga menghasilkan catatan lapangan, kemudian memilah-milahnya, selanjutnya peneliti merumuskan pengembangan atraksi wisata minat khusus berbasis nilai Tradisi Makotek yang dapat dikembangkan di Desa Wisata Munggu.

\section{III.HASIL DAN PEMBAHASAN}

\section{A. Desa Wisata Munggu dan Tradisi Makotek}

Sejak dibentuknya Desa Wisata Munggu, belum banyak perkembangan hingga dibentuknya Pokdarwis (Kelompok Sadar Wisata) lewat SK Desa Munggu no. 25 tahun 2017. Sejak saat itu Desa Wisata Munggu berkembang mulai dari pemetaan potensi wisata, sosialisasi ke seluruh masyarakat melalui desa adat dan desa dinas, hingga berjalannya program-program yang fokus menunjang perkembangan pariwisata.

Desa Wisata Munggu memiliki 6 potensi pariwisata dan salah satunya adalah Tradisi Makotek, selain Pantai Munggu, Tukad Penet, Pangelukatan Pancoran Garuda, area persawahan yang masih sangat luas, dan ayunan yang digerakkan dengan tenaga manusia dan beroperasi setiap Hari Raya Kuningan. Desa Wisata Munggu memiliki beberapa fasilitas pariwisata seperti villa, guest house, bungalow, rumah makan, money changer, rent car. Terdapat berbagai kegiatan wisata yang bisa dilakukan di seperti trekking sawah, merangkai gebogan carang sari, wood carving, cooking class, sunset dinner, belajar tari tradisional, belajar gambelan, camping di dekat pantai, dan berfoto tempat selfie di pinggir pantai. Pemerintah desa juga rutin menggelar acara seperti lomba layanglayang di bulan Juni dan Juli, program bersihbersih pantai, pelepasan tukik, penanaman pohon, dll.

Walaupun kurang intensif, banyak pihak yang telah membantu Desa Wisata Munggu dimulai dari pemerintah dengan pendanaan dan perencanaan, instansi pendidikan lewat pelatihan Bahasa Inggris dan pelatihan wirausaha, pengusaha pariwisata dalam penyediaan fasilitas pariwisata dan lain-lain. Selain LPD, baru dibentuk Bumdes Tri Guna Sejahtera yang diharapkan mampu berpartisipasi dan menggerakkan roda ekonomi di Desa Wisata Munggu.

Tradisi Makotek merupakan jati diri masyarakat Munggu, bahkan dilambangkan dengan gambar tombak dan tameng perunggu yang terdapat pada lambang Desa Munggu. Sejarah Desa Munggu juga berkaitan erat dengan Tradisi Makotek. Bercerita tentang pasukan Munggu yang diceritakan sebagai pasukan 
Kerajaan Mengwi yang gagah berani. Pasukan yang dikenal sebagai pasukan Ki Guwak Selem (gagak hitam) ini dipimpin oleh Raja Munggu sebagai utusan Kerajaan Mengwi. Raja Munggu dan pasukannya diutus untuk mengalahkan musuh, lalu berhasil melakukannya setelah mendapatkan benda pusaka berupa tameng perunggu. Tameng perunggu yang dipercaya sebagai benda pusaka itu tetap dihormati hingga kini dan diarak setiap Hari Raya Kuningan pada saat Tradisi Makotek dan dapat dilihat pada gambar 3.1 sebagai berikut.

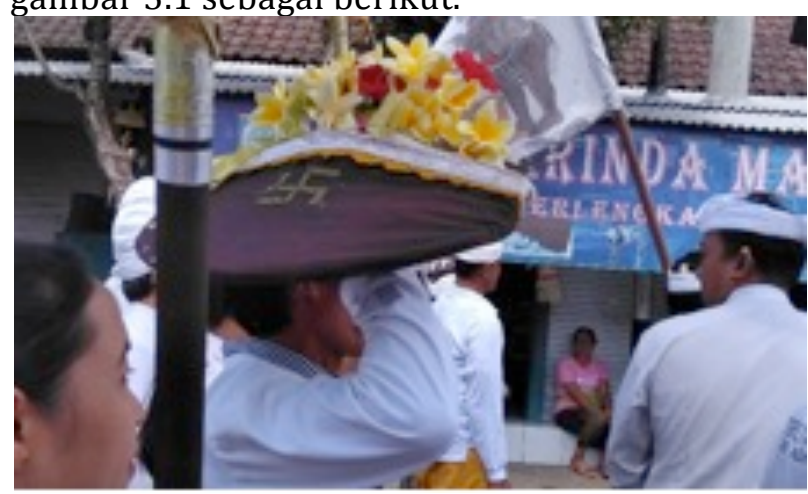

Gambar 3.1 Tameng perunggu Desa Munggu Sumber: Dokumen Peneliti

Sepulangnya dari pertempuran, pasukan yang tinggal di Kerajaan Munggu menyambut dengan gembira. Masing-masing pasukan berjalan beriringan membawa tombak hingga terdengar bunyi " tek.. tek.. tek.." yang akhirnya menjadi asal-usul nama Tradisi Makotek. Tradisi Makotek masih dilaksanakan hingga kini setiap Hari Raya Kuningan sebagai cara masyarakat menghormati leluhur, melestarikan budaya serta menjalankan kepercayaan yang mereka anut. Masyarakat laki-laki dari tiap banjar membawa kayu pulet kira-kira 3 meter yang menyerupai tombak dan diujungnya dihias dengan tamiang janur dan daun pandan. Mereka melakukan persembahyangan terlebih dahulu di Pura Puseh lan Desa Adat Munggu lalu mengarak tameng perunggu ke Griya Dalem Wisesa, Pura Luhur Sapuh Jagat dan kembali lagi ke Pura Puseh lan Desa Adat Munggu.

\section{B. Nilai Tradisi Makotek}

\section{Nilai Pengungkapan (Presentation)}

Tradisi Makotek juga menunjukkan nilai bakat megambel/tabuh yang dimiliki oleh masyarakat Desa Munggu. Bakat mengambel ini juga terus diasah lewat berbagai kesempatan seperti adanya Sanggar Seni, Sekaa Teruna Tunjung Mekar, dan bahkan adanya Parade Baleganjur yang diadakan oleh Pemerintah Desa Munggu.
Pada ujung kayu pulet digantungkan tamiang janur untuk melambangkan tameng perunggu yang merupakan benda pusaka Desa Munggu. Tamiang janur ini dibuat sendiri atau dibeli dari penjual lokal sebelum pelaksanaan Tradisi Makotek. Pembuatan tamiang janur ini menunjukkan nilai keterampilan yang terkandung dalam Tradisi Makotek. Para peserta Tradisi Makotek membawa kayu pulet yang telah digantungkan tamiang janur pada ujungnya dapat dilihat pada gambar 3.2 sebagai berikut.

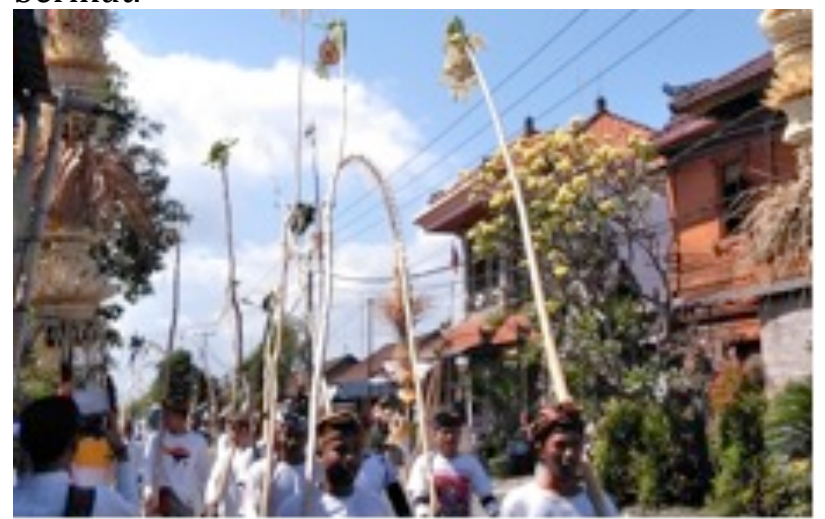

Gambar 3.2 Tamiang janur pada ujung kayu pulet

Sumber: Dokumen Peneliti

Nilai pengungkapan Tradisi Makotek dapat disajikan dalam tabel 3.1 sebagai berikut.

Tabel 3.1 Nilai Pengungkapan Tradisi Makotek

\begin{tabular}{|c|c|}
\hline $\begin{array}{l}\text { Nilai } \\
\text { Pengungkapan }\end{array}$ & Keterangan \\
\hline Nilai Bakat & $\begin{array}{l}\text { Nilai bakat ditunjukkan lewat } \\
\text { bakat tabuh yang dilakukan } \\
\text { oleh pemain gambelan } \\
\text { baleganjur. }\end{array}$ \\
\hline $\begin{array}{l}\text { Nilai } \\
\text { Keterampilan }\end{array}$ & $\begin{array}{l}\text { Nilai keterampilan } \\
\text { ditunjukkan lewat pembuatan } \\
\text { tamiang janur yang } \\
\text { digantungkan pada ujung kayu } \\
\text { pulet. }\end{array}$ \\
\hline Nilai Medium & $\begin{array}{l}\text { Nilai medium ditunjukkan } \\
\text { lewat kayu pulet yang } \\
\text { merupakan kayu asli Bali yang } \\
\text { mudah didapatkan dan } \\
\text { memiliki struktur yang kuat } \\
\text { dan tahan lama. }\end{array}$ \\
\hline
\end{tabular}

Sumber: Dokumen Peneliti

2. Nilai Isi (Content)

Pelaksanaan Tradisi Makotek dilakukan untuk menghormati sejarah. Hal ini menunjukkan nilai pengetahuan dari Tradisi Makotek. Pihak yang melakukan Tradisi Makotek adalah masyarakat lokal Desa Munggu yaitu orang Bali dan ini menunjukkan nilai ras dari Tradisi Makotek. 
Tradisi Makotek mengungkapkan rasa kebahagiaan pasukan Munggu yang merayakan kemenangan. Kegagahan tentara Munggu di masa lalu diungkapkan lewat gerakan yang dilakukan masyarakat Munggu ketika menyatukan kayu pulet untuk membentuk kerucut dan seseorang yang berani akan memanjat hingga ke puncak kerucut itu. Mereka meyakini pelaksanaan Tradisi Makotek adalah cara tolak bala. Hal-hal tersebut menunjukkan nilai intuisi/bawah sadar dari Tradisi makotek. Dalam Agama Hindu, terdapat filosofi kehidupan masyarakat Bali yang menjadi pedoman hidup sehari-hari seperti Tri Hita Karana. Hal ini menunjukkan nilai gagasan dari Tradisi Makotek.

Tradisi Makotek diikuti laki-laki masyarakat Desa Munggu dari 15 tahun hingga 50 tahun. Hal ini berarti relasi antar generasi yang ada di Desa Munggu berjalan dengan baik. Selain itu juga berarti semua generasi peduli akan pelestarian budaya tradisional ini. Generasi muda sudah memiliki keinginan untuk berpartisipasi dan generasi senior juga mendukung dan memberikan pengetahuan untuk diajarkan kepada generasi muda untuk meneruskan praktek Tradisi Makotek bahkan di era globalisasi ini. Hal ini menunjukkan nilai moral dan nilai sosial yang juga merupakan bagian dari nilai pesan/hidup dari Tradisi Makotek. Adanya kepercayaan masyarakat Munggu tentang Tradisi Makotek juga dipengaruhi oleh Tradisi Makotek yang memiliki nilai sakral. Karena itu, masyarakat Munggu mempercayai Tradisi Makotek sebagai tradisi tolak bala. Hal-hal ini menunjukkan nilai religi yang juga merupakan bagian dari nilai pesan/hidup dari Tradisi Makotek.

Nilai isi Tradisi Makotek dapat disajikan dalam tabel 3.2 sebagai berikut.

Tabel 3.2 Nilai Isi Tradisi Makotek

\begin{tabular}{ll}
\hline Nilai Isi & Keterangan \\
\hline \multirow{4}{*}{ Nilai } & Nilai pengetahuan ditunjukkan \\
pengetahuan & lewat alur proses yang \\
& menunjukkan sejarah Desa \\
& Munggu dan Tradisi Makotek \\
& secara khusus. \\
\hline Nilai ras & Nilai ras ditunjukkan lewat orang \\
& yang menjalankan tradisi ini \\
& adalah masyarakat lokal Desa \\
\hline Nilai & Munggu yaitu orang Bali. \\
intuisi/bawah & Nilai intuisi ditunjukkan lewat \\
sadar & gerakan yang dilakukan \\
& bermakna kegagahan tentara
\end{tabular}

Munggu yaitu Ki Guwak Selem.

Selain itu, keyakinan masyarakat

Lanjutan Tabel 3.2

\begin{tabular}{|c|c|}
\hline Nilai Isi & Keterangan \\
\hline & $\begin{array}{l}\text { Munggu dengan melaksanakan } \\
\text { tradisi ini dapat menjadi tolak } \\
\text { bala, baik untuk wabah penyakit } \\
\text { hingga hama pertanian yang } \\
\text { menjadi mata pencaharian } \\
\text { mayoritas di Desa Munggu }\end{array}$ \\
\hline Nilai gagasan & $\begin{array}{l}\text { Nilai gagasan ditunjukkan lewat } \\
\text { manifestasi filosofi Bali seperti } \\
\text { Tri Hita Karana dalam } \\
\text { pelaksanaan Tradisi Makotek. }\end{array}$ \\
\hline $\begin{array}{l}\text { Nilai } \\
\text { pesan/hidup } \\
\text { (nilai moral, } \\
\text { nilai sosial, } \\
\text { nilai religi) }\end{array}$ & $\begin{array}{l}\text { Nilai moral ditunjukkan lewat } \\
\text { kemauan masyarakat Munggu } \\
\text { untuk tetap melestarikan budaya } \\
\text { tradisional yang dimilikinya. Nilai } \\
\text { sosial ditunjukkan lewat } \\
\text { partisipasi dari berbagai } \\
\text { kalangan sosial dari generasi } \\
\text { muda hingga generasi senior } \\
\text { yang mau mengambil bagian } \\
\text { dalam kebersamaan. Nilai religi } \\
\text { ditunjukkan lewat fungsi Tradisi } \\
\text { Makotek sebagai bagian dari } \\
\text { upacara Ngrebeg/tolak bala. }\end{array}$ \\
\hline
\end{tabular}

Sumber: Dokumen Peneliti

3. Nilai Penampilan (Appearance)

Nilai struktur dari Tradisi Makotek ditampilkan lewat kayu-kayu yang membentuk kerucut yang melabangkan tujuan yang ingin dicapai masyarakat Munggu yaitu kesejahteraan. Dengan begitu pemuda yang memanjat kerucut tersebut dapat berarti perjuangan mencapai tujuan dan dapat dilihat pada gambar 3.3 sebagai berikut.

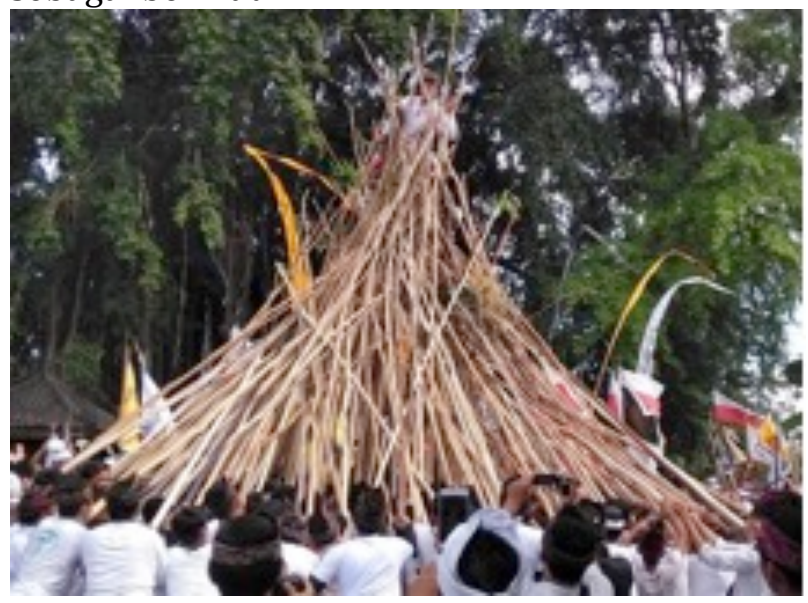

Gambar 3.3 Kayu pulet membentuk kerucut dan seseorang berusaha naik ke puncaknya

Sumber: Dokumen Peneliti

Kayu pulet yang menjadi properti utama yang digunakan dalam Tradisi Makotek 
mengandung nilai bentuk yang menyerupai tombak. Tombak dianggap sebagai senjata memiliki kekuatan yang melambangkan semangat masyarakat Munggu di masa lalu sebagai bala tentara kerajaan. Selain itu modifikasi yang dilakukan dengan menambahkan daun pandan berduri sebagai pengganti ujung tombak yang tajam serta mengantungkan janur berbentuk tamiang sebagai lambang perisai juga memperkuat manifestasi tombak pada properti kayu pulet tersebut.

Nilai penampilan Tradisi Makotek dapat disajikan dalam tabel 3.3 sebagai berikut.

\section{Tabel 3.3 Nilai Penampilan Tradisi Makotek}

\begin{tabular}{ll}
\hline $\begin{array}{l}\text { Nilai } \\
\text { penampilan }\end{array}$ Keterangan \\
\hline
\end{tabular}

Nilai bentuk ditunjukkan lewat properti yang digunakan dalam Tradisi Makotek. Properti utama yaitu kayu pulet yang menyerupai tongkat tombak. Daun pandan yang diikatkan di ujung kayu melambangkan ketajaman ujung tombak. Selain itu, digantungkan juga janur berbentuk tamiang sebagai lambang perisai perunggu. Tombak dan perisai perunggu Nilai wujud merupakan barang yang dianggap (nilai bentuk, senjata suci yang mampu nilai struktur) menghantarkan Munggu pada kemenangan/kejayaan. Nilai struktur kerucut yang dibentuk menggunakan kayu-kayu pulet tersebut adalah simbol kemenangan, persatuan, hingga tujuan masyarakat Munggu untuk mencapai kesejahteraan. Dengan perlambang itu maka, pemuda yang berani memanjat kerucut itu merupakan gambaran orang yang sedang berusaha keras mencapai tujuan hidupnya.

\section{Sumber: Dokumen Peneliti}

\section{Pengembangan Atraksi Wisata Minat Khusus Berbasis Nilai Makotek}

\section{Something to see}

Hal yang bisa dilakukan untuk mengembangkan atraksi wisata tersebut adalah membentuk information center tentang Tradisi Makotek. Tidak perlu berbentuk gedung formal seperti museum, namun dapat berupa seperti sanggar tari yang dikelola oleh masyarakat lokal. Hal ini akan membantu wisatawan yang datang untuk melihat Tradisi Makotek namun tidak bisa datang persis pada Hari Raya Kuningan. Pada information center ini, bisa dijelaskan sejarah Tradisi Makotek, unsur-unsur tari dan tabuh, foto, hingga video dokumentasi Makotek. Selain itu bisa ditampilkan teater pariwisata.

Nilai hidup dari Tari Makotek juga bisa ditunjukkan kepada wisatawan dengan menunjukkan dan memberitahukan budaya ngayah yang biasa dilakukan masyarakat menjelang piodalan di pura.

Dapat dibentuk sendra tari baru yang dapat dinikmati wisatawan yang bercerita tentang sejarah Desa Munggu dan lahirnya Tradisi Makotek. Sendra tari ini harus benarbenar bersifat hiburan, tanpa menyentuh unsur sakral, namun tetap menunjukkan nilai-nilai Tradisi Makotek. Sendra tari baru ini diharapkan mampu menarik wisatawan untuk berkunjung ke Desa Wisata Munggu.

Dalam pengembangan atraksi wisata minat khusus yang berbasis nilai Tradisi Makotek ini telah dipenuhi kriteria enriching dan learning. Enriching berarti memperkaya pengetahuan baik wisatawan maupun masyarakat lewat observasi dan mendengarkan. Pengetahuan mengenai sejarah, proses persiapan sebelum pelaksanaan serta prosesi Tradisi Makotek dari awal hingga akhir. Learning dapat berarti memberikan kesempatan bagi wisatawan untuk belajar bahkan hanya dengan melihat. Pengembangan atraksi wisata something to see dapat disajikan dalam tabel 3.4 sebagai berikut.

Tabel 3.4 Pengembangan Atraksi Wisata Something to See

\begin{tabular}{|c|c|c|}
\hline Something to see & $\begin{array}{l}\text { Nilai Tradisi } \\
\text { Makotek }\end{array}$ & $\begin{array}{l}\text { Kriteria } \\
\text { REAL }\end{array}$ \\
\hline $\begin{array}{l}\text { membuat } \\
\text { information center } \\
\text { tentang Tradisi } \\
\text { Makotek }\end{array}$ & $\begin{array}{l}\text { nilai isi (nilai } \\
\text { pengetahuan) }\end{array}$ & $\begin{array}{l}\text { memenuhi } \\
\text { kriteria } \\
\text { enriching dan } \\
\text { learning }\end{array}$ \\
\hline $\begin{array}{l}\text { melihat proses } \\
\text { persiapan } \\
\text { sebelum } \\
\text { pelaksaaan } \\
\text { Tradisi Makotek } \\
\text { (ngayah) }\end{array}$ & $\begin{array}{l}\text { nilai isi (nilai } \\
\text { hidup) }\end{array}$ & $\begin{array}{l}\text { memenuhi } \\
\text { kriteria } \\
\text { enriching dan } \\
\text { learning }\end{array}$ \\
\hline $\begin{array}{l}\text { melihat sendra } \\
\text { tari baru yang } \\
\text { menggambarkan } \\
\text { sejarah Desa } \\
\text { Munggu dan } \\
\text { Tradisi Makotek }\end{array}$ & $\begin{array}{l}\text { nilai isi (nilai } \\
\text { pengetahuan) }\end{array}$ & $\begin{array}{l}\text { memenuhi } \\
\text { kriteria } \\
\text { enriching dan } \\
\text { learning }\end{array}$ \\
\hline
\end{tabular}

Sumber: Dokumen Peneliti

2.Something to do 
Nilai keterampilan ditunjukkan dengan mengajarkan wisatawan membuat tamiang dari janur yang biasa dipasang di ujung kayu kotekan yang dipakai dalam Tradisi Munggu. Nilai sosial bisa ditunjukkan kepada wisatawan dengan melakukan penanaman pohon kayu pulet. Wisatawan bisa diberikan informasi mengenai perkembangan pohon tersebut. Hal ini juga dilakukan karena kayu pulet yang digunakan masyarakat Munggu sekarang tidak seluruhnya didapat dari Desa Munggu melainkan desa-desa sekitar Munggu seperti Desa Beraban, Desa Tumbak Bayuh dan Desa Pererenan.

Nilai bakat dan nilai pengetahuan bisa ditunjukkan kepada wisatawan dengan belajar sendra tari baru serta tabuhnya. Saat Parade Baleganjur berlangsung dalam rangka Porsenides, wisatawan bisa diajak untuk tampil mengisi acara di panggung setelah belajar tabuh secara sederhana.

Selain itu wisatawan juga bisa diajak mengunjungi tempat-tempat bersejarah di Desa Munggu. Selagi berkeliling, wisatawan juga bisa mencari dan mengetahui pohon kayu pulet yang menunjukkan nilai bentuk dan nilai medium dari Tradisi Makotek. Membuat sharing session di information center juga bisa dilakukan antara wisatawan dan masyarakat lokal yang menunjukkan nilai pengetahuan.

Dalam pengembangan atraksi wisata minat khusus yang berbasis nilai Tradisi Makotek ini, rewarding dapat berarti membentuk cara agar atraksi yang ada dapat memberikan kontribusi terhadap masyarakat dan menimbulkan rasa bangga terhadap wisatawan yang melakukan kegiatan pariwisata.

Dalam pengembangan atraksi wisata minat khusus yang berbasis nilai Tradisi Makotek ini, enriching dan learning dapat berarti memberi pengetahuan tidak hanya kepada wisatawan tapi juga kepada masyarakat. Atraksi yang bisa dikembangkan seperti membentuk sharing session pada information center di mana wisatawan bisa belajar dari masyarakat mengenai budaya lokal masyarakat Munggu. Wisatawan bisa mengetahui lebih banyak tentang Tradisi Makotek.

Dalam pengembangan atraksi wisata minat khusus yang berbasis nilai Tradisi Makotek ini, adventuring dapat berarti membentuk atraksi yang memberikan sensasi petualangan. Aktraksi yang bisa dikembangkan adalah mengajak wisatawan berkeliling sekitar desa untuk mengetahui tempat-tempat yang dianggap bersejarah (napak tilas) dan diajak mengenal pohon kayu pulet di sekitar desa.

Mengacu pada awig-awig dan perarem yang berlaku di Desa Munggu, wisatawan diperbolehkan mengikuti Trasidi Makotek asal mengikuti peraturan yang ada. Peraturan tersebut seperti mengikuti sembahyang di Pura Dalem sebelum pelaksanaan, berpakaian sesuai aturan yaitu pakaian adat madia, serta tidak melakukan/menimbulkan hal-hal negatif selama pelaksanaan Tradisi Makotek. Wisatawan diperbolehkan mengikuti Tradisi Makotek dan dapat dilihat pada gambar 3.4 sebagai berikut.

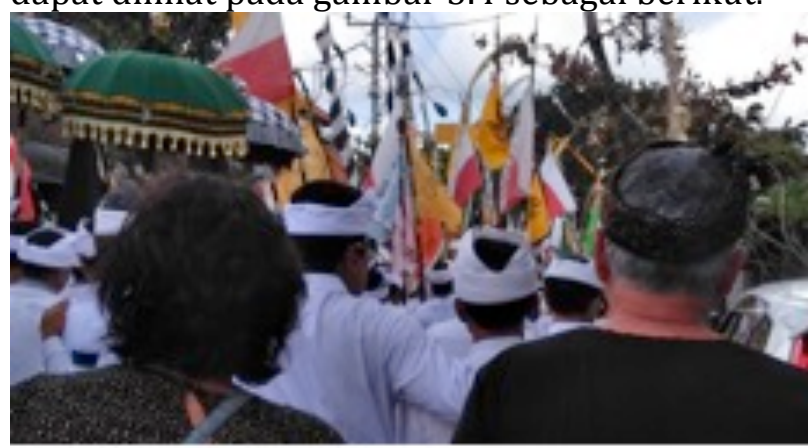

Gambar 3.3 Wisatawan mancanegara yang mengikuti rombongan dalam Tradisi Makotek

Sumber: Dokumen Peneliti

Pengembangan atraksi wisata something to do dapat disajikan dalam tabel 3.5 sebagai berikut.

Tabel 3.5 Pengembangan Atraksi Wisata Something to Do

\begin{tabular}{|c|c|c|}
\hline $\begin{array}{l}\text { Something to } \\
\text { do }\end{array}$ & $\begin{array}{l}\text { Nilai Tradisi } \\
\text { Makotek }\end{array}$ & $\begin{array}{l}\text { Kriteria } \\
\text { REAL }\end{array}$ \\
\hline $\begin{array}{l}\text { mengajarkan } \\
\text { cara membuat } \\
\text { tamiang janur }\end{array}$ & $\begin{array}{l}\text { nilai } \\
\text { pengungkapan } \\
\text { (nilai } \\
\text { keterampilan) }\end{array}$ & $\begin{array}{l}\text { memenuhi } \\
\text { kriteria } \\
\text { learning }\end{array}$ \\
\hline $\begin{array}{l}\text { mengajak } \\
\text { wisatawan } \\
\text { melakukan } \\
\text { penanaman } \\
\text { pohon kayu } \\
\text { pulet }\end{array}$ & $\begin{array}{l}\text { nilai isi (nilai } \\
\text { sosial) }\end{array}$ & $\begin{array}{l}\text { memenuhi } \\
\text { kriteria } \\
\text { rewarding }\end{array}$ \\
\hline $\begin{array}{l}\text { mengajarkan } \\
\text { wisatawan cara } \\
\text { menabuh } \\
\text { gambelan } \\
\text { baleganjur }\end{array}$ & $\begin{array}{l}\text { nilai } \\
\text { pengungkapan } \\
\text { (nilai bakat) }\end{array}$ & $\begin{array}{l}\text { memenuhi } \\
\text { kriteria } \\
\text { learning }\end{array}$ \\
\hline $\begin{array}{l}\text { mengajak } \\
\text { wisatawan } \\
\text { belajar sendra } \\
\text { tari baru dan } \\
\text { tabuhnya }\end{array}$ & $\begin{array}{l}\text { nilai isi (nilai } \\
\text { pengetahuan) }\end{array}$ & $\begin{array}{l}\text { memenuhi } \\
\text { kriteria } \\
\text { enriching dan } \\
\text { learning }\end{array}$ \\
\hline $\begin{array}{l}\text { mengajak } \\
\text { wisatawan }\end{array}$ & $\begin{array}{l}\text { nilai isi (nilai } \\
\text { pengetahuan) }\end{array}$ & $\begin{array}{l}\text { memenuhi } \\
\text { kriteria }\end{array}$ \\
\hline
\end{tabular}




\begin{tabular}{|c|c|c|}
\hline $\begin{array}{l}\text { berkeliling } \\
\text { tempat } \\
\text { bersejarah di } \\
\text { Desa Munggu }\end{array}$ & & $\begin{array}{l}\text { learning dan } \\
\text { adventuring }\end{array}$ \\
\hline $\begin{array}{l}\text { mengajak } \\
\text { wisatawan } \\
\text { berkeliling } \\
\text { mencari dan } \\
\text { mengetahui } \\
\text { pohon kayu } \\
\text { pulet }\end{array}$ & $\begin{array}{l}\text { nilai penampilan } \\
\text { (nilai bentuk), } \\
\text { nilai } \\
\text { pengungkapan } \\
\text { (nilai medium) }\end{array}$ & $\begin{array}{l}\text { memenuhi } \\
\text { kriteria } \\
\text { learning dan } \\
\text { adventuring }\end{array}$ \\
\hline $\begin{array}{l}\text { membuat } \\
\text { sharing session } \\
\text { di information } \\
\text { center untuk } \\
\text { wisatawan dan } \\
\text { masyarakat } \\
\text { bisa } \\
\text { berinteraksi } \\
\end{array}$ & $\begin{array}{l}\text { nilai isi (nilai } \\
\text { pengetahuan) }\end{array}$ & $\begin{array}{l}\text { memenuhi } \\
\text { kriteria } \\
\text { enriching dan } \\
\text { learning }\end{array}$ \\
\hline $\begin{array}{l}\text { mengajak } \\
\text { wisatawan ikut } \\
\text { berpartisipasi } \\
\text { di Tradisi } \\
\text { Makotek }\end{array}$ & $\begin{array}{l}\text { nilai isi (nilai ras, } \\
\text { nilai intuisi, nilai } \\
\text { gagasan) }\end{array}$ & $\begin{array}{l}\text { memenuhi } \\
\text { kriteria } \\
\text { rewarding, } \\
\text { enriching, } \\
\text { adventuring, } \\
\text { dan learning }\end{array}$ \\
\hline
\end{tabular}

Sumber: Dokumen Peneliti

\section{Something to buy}

Masih belum banyak hal yang bisa dibeli wisatawan sebagai souvenir dari Desa Wisata Munggu. Ada beberapa industri lokal seperti kacang goreng dan kerupuk. Selain itu juga ada industri lokal seperti kerajinan besi/keris, ukiran, hingga hiasan penjor. Perlu ada perhatian khusus untuk pengemasan kacang dan kerupuk jika memang ingin dijadikan oleh-oleh. Selain itu, Desa Wisata Munggu juga bisa menawarkan merchandise yang berkarakter Munggu. Nilai keterampilan juga bisa ditunjukkan dalam proses mendesign souvenir yang menarik dan sesuai dengan karakter Desa Wisata Munggu.

Dalam pengembangan atraksi wisata minat khusus yang berbasis nilai Tradisi Makotek ini, rewarding dapat berarti membuat wisatawan puas dengan barang yang ia beli. Hal yang bisa mendukung hal tersebut misalnya membeli tumbler, sedotan bambu, alat makan dari kayu yang mempromosikan sustainable tourism/pariwisata berkelanjutan. Dengan begitu wisatawan bisa mendapatkan produk dan merasa ia telah berkontribusi menyumbang pendapatan ekonomi serta menjadi wisatawan yang bijak dalam mendukung pariwisata berkelanjutan. Pengembangan atraksi wisata something to buy dapat disajikan dalam tabel 3.6 sebagai berikut.

Tabel 3.6 Pengembangan Atraksi Wisata Something to Buy

\begin{tabular}{lll}
\hline $\begin{array}{l}\text { Something to } \\
\text { buy }\end{array}$ & $\begin{array}{l}\text { Nilai Tradisi } \\
\text { Makotek }\end{array}$ & $\begin{array}{l}\text { Kriteria } \\
\text { REAL }\end{array}$ \\
\hline membeli & nilai & memenuhi \\
merchandise & pengungkapan & kriteria \\
berkarakter & (nilai & rewarding \\
Munggu & keterampilan) & \\
\hline
\end{tabular}

Sumber: Dokumen Peneliti

\section{IV.SIMPULAN DAN SARAN}

\section{A. Simpulan}

Tradisi Makotek adalah tradisi yang sangat kental dengan budaya khas masyarakat Desa Munggu. Akan sangat ideal bila, pariwisata yang ada di Desa Wisata Munggu juga mampu menjiwai nilai-nilai yang terkandung pada Tradisi Makotek. Hal ini bisa dilakukan lewat pengembangan atraksi wisata minat khusus berbasis nilai Tradisi Makotek. Berdasarkan hasil penelitian yang berjudul Pengembangan Atraksi Wisata Minat Khusus Berbasis Nilai Tradisi Makotek Di Desa Wisata Munggu Badung Bali, maka dapat ditarik kesimpulan sebagai berikut.

Tradisi Makotek memiliki nilai pengungkapan, nilai isi, dan nilai penampilan. Nilai pengungkapan Tradisi Makotek adalah nilai bakat, nilai keterampilan, serta medium. Nilai isi Tradisi Makotek adalah nilai pengetahuan, nilai ras, nilai intuisi, nilai gagasan, nilai pesan/hidup (nilai moral, nilai sosial, nilai religi). Nilai penampilan Tradisi Makotek adalah nilai wujud (nilai bentuk dan nilai struktur).

Atraksi wisata yang ada akan lebih baik bila mampu merepresentasikan nilai Tradisi Makotek. Hal ini bisa dilakukan dalam pengembangan atraksi lewat something to see, something to do, dan something to buy.

Untuk something to see, dapat dibentuk sebuah information center yang mampu memberikan informasi mengenai Tradisi Makotek dan menjadi tempat dilaksanakannya teater pariwisata. Tidak hanya itu, wisatawan juga bisa diajak melihat kegiatan ngayah yang dilakukan masyarakat Desa Munggu menjelang Tradisi Makotek. Wisatawan dapat menonton sendra tari baru. Hal ini merepresentasikan nilai isi yaitu nilai pengetahuan dan nilai hidup Tradisi Makotek. Pengembangan atraksi wisata minat khusus memenuhi kriteria enriching dan learning. 
Untuk something to do, wisatawan bisa belajar membuat tamiang janur, melakukan penanaman pohon kayu pulet, menabuh gamelan baleganjur, menari sendra tari baru sejarah Desa Munggu, berkeliling ke tempat bersejarah (napak tilas), melihat pohon kayu pulet, membuat sharing session, berpartisipasi pada Tradisi Makotek. Hal ini merepresentasikan nilai pengungkapan (nilai keterampilan, nilai bakat, nilai medium), nilai isi (nilai sosial, nilai pengetahuan, nilai intuisi, nilai gagasan), serta nilai penampilan (nilai bentuk, nilai struktur) Tradisi Makotek. Pengembangan atraksi wisata minat khusus memenuhi kriteria rewarding, enriching, adventuring, dan learning (REAL).

Untuk something to buy, wisatawan bisa membeli oleh-oleh/cinderamata yang berkarakter Munggu. Hal ini merepresentasikan nilai keterampilan Tradisi Makotek. Pengembangan atraksi wisata minat khusus memenuhi kriteria rewarding.

\section{B. Saran}

Berdasarkan hasil penelitian yang telah dilakukan, dapat disarankan beberapa hal sebagai berikut.

1. Tabuh, tari tradisional harus tetap dilestarikan. Sendra tari baru tentang sejarah Desa Munggu yang berfungsi sebagai tari balihbalihan bisa dikembangkan yang tidak memuat nilai sakral Tradisi Makotek sama sekali.

2. Fungsi Tradisi Makotek sebagai tradisi tolak bala harus tetap dipertahankan. Penegakan awig-awig dan perarem harus lebih diperjelas bila wisatawan akhirnya diperbolehkan mengikuti dan mengambil bagian pada Tradisi Makotek.

3. Kayu pulet yang menjadi properti utama Tradisi Makotek perlu lebih diperhatikan. Akan lebih baik disediakan lahan untuk menanam pohon kayu pulet agar kayu pulet yang digunakan nantinya benar-benar menjadi trademark Desa Munggu.

4. Bila Sendra Tari baru mengenai sejarah Desa Munggu telah ditimbang dan diperbolehkan untuk dibuat, semua masyarakat harus mengetahuinya. Perlu ada persetujuan dari masyarakat sebagai pemilik budaya tersebut. Selain itu, sendra tari ini akan lebih baik bila akhirnya melibatkan lebih banyak masyarakat lokal, contoh sebagai penari, penabuh, pelatih.

5. Perlu ada kerja sama dengan para pihak yang berkaitan dalam aktivitas yang akan dikembangkan, contohnya menjalin kerja sama dengan sanggar seni lokal, sekaa teruna teruni, dan stakeholder lain.

6. Design merchandise berkarakter Munggu dan Makotek bisa merupakan karya masyarakat lokal dan juga bisa diproduksi langsung oleh masyarakat lokal. Hal ini dapat memperkuat autentisitas dan menambah pendapatan ekonomi masayrakat. Cinderamata ini akan menjadi kenang-kenangan bagi wisatawan dan dapat memungkinkan mereka datang kembali ke Desa Wisata Munggu.

\section{DAFTAR PUSTAKA/REFERENSI}

Bungin, Burham. 2007. Penelitian Kualitatif. Jakarta: Prenada Media Group.

Djayus, Nyoman, B.A. 1980. Teori Tari Bali. Denpasar : CV. Sumber Mas Bali.

Douglas, N. \& Derrett R. (2001). Special Interest Tourism. Australia: John Wiley \& Sons

Fandeli. 2002. Perencanaan Kepariwisataan Alam. Yogyakarta: Universitas Gajah Mada.

Leckerkerker, C. 1923. Blambangan. Bataviash: Indische Gids I.

Marwati, Djoened Poesponegoro dkk. 1984. Sejarah Nasional Indonesia Jilid II dan V. Jakarta: Balai Pustaka.

Moleong J, Lexy. 1999. Metodologi Penelitian Kualitatif. Bandung: Remaja Rosdakarya.

Pitana, I Gd. 2005. Sosiologi Pariwisata, Kajian Sosiologi terhadap Struktur, Sistem dan Dampak-Dampak Pariwisata. Yogyakarta: Andi.

Purwaningsih, Ni Putu Enik dan I Gusti Agung Oka Mahagangga. 2018. Hambatan Desa Munggu sebagai Desa Wisata di Kabupaten Badung. Jurnal Destinasi Pariwisata Vol. 5 No. 2

Pradana, Gede Yoga Kharisma. 2016. Tradisi Makotek di Desa Munggu, Badung pada Era Global. Disertasi Program Studi Kajian Budaya Pascasarjana Universitas Udayana.

Sudana, I. P. 2013. Strategi Pengembangan Desa Wisata Ekologis Di Desa Belimbing, Kecamatan Pupuan Kabupaten Tabanan. Analisis Pariwisata, 13(1), 11-31.

Sugiyono. 2010. Metode Penelitian Kuantitatif, Kualitatif dan R\&D. Bandung: Alfabeta

Sumarjo, Yakob. 2000. Filsafat Seni. Bandung: Penerbit ITB.

Wiryani, Ni Made. 2011. Bentuk, Perkembangan, dan Fungsi Tari Mekotekan. Artikel Institut Seni Indonesia Denpasar Bulan September 2 (9). p.1.

Yoeti, Oka A. 1996. Pengantar Ilmu Pariwisata. Bandung : Angkasa.

Yoeti, Oka A. 1997. Perencanaan dan Pengembangan Pariwisata. Jakarta: Pradnyana Paramita

Peraturan Perundang-undangan:

Undang-Undang Nomor 10 Tahun 2009 tentang Kepariwisataan. Lembaran Negara Republik Indonesia Nomor 11 Tahun 2009. Tambahan Lembaran Negara Republik Indonesia Nomor 4966.

Peraturan Daerah Provinsi Bali No. 2 Tahun 2012 tentang Kepariwisataan Budaya Bali. Lembaran Daerah Provinsi Bali Nomor 2 Tahun 2012. Tambahan Lembaran Daerah Provinsi Bali Nomor 2.

Peraturan Bupati Badung no. 47 Tahun 2010 tentang Penetapan Kawasan Desa Wisata di Kabupaten Badung. Berita Daerah Kabupaten Badung Nomor 44 Tahun 2010. 